\title{
High Breakdown Strength, Multilayer Ceramics for Compact Pulsed Power Applications
}

Federal Manufacturing \& Technologies
M. L. Krogh and
B. C. Schultz, FM\&T;
W. Huebner,
S. C. Zhang, and
B. Gilmore, University of Missouri-Rolla;
R. C. Pate,
L. F. Rinehart, and
J. M. Lundstrom, Sandia National Laboratory/New Mexico

KCP-613-6212

Published July 1999

Approved for public release; distribution is unlimited.

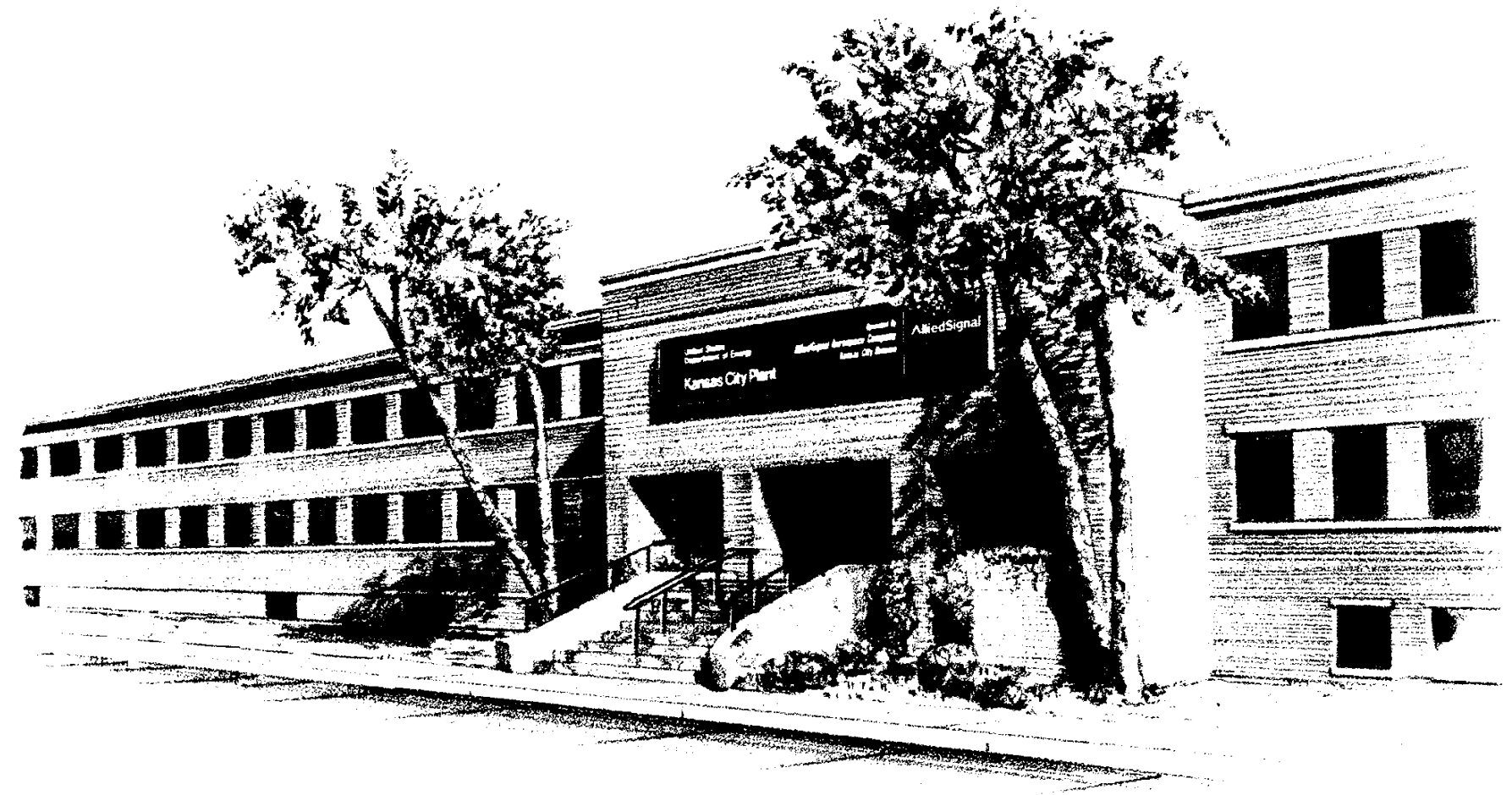

Prepared Under Contract Number DE-ACO4-76-DP00613 for the United States Department of Energy 


\section{DISCLAIMER}

This report was prepared as an account of work sponsored by an agency of the United States Government. Neither the United States Government nor any agency thereof, nor any of their employees, makes any warranty, express or implied, or assumes any legal liability or responsibility for the accuracy, completeness, or usefulness of any information, apparatus, product, or process disclosed, or represents that its use would not infringe privately owned rights. Reference herein to any specific commercial product, process, or service by trade names, trademark, manufacturer, or otherwise, does not necessarily constitute or imply its endorsement, recommendation, or favoring by the United States Government or any agency thereof. The views and opinions of authors expressed herein do not necessarily state or reflect those of the United States Government or any agency thereof.

Printed in the United States of America.

This report has been reproduced from the best available copy.

Available to DOE and DOE contractors from the Office of Scientific and Technical Information,

P. O. Box 62, Oak Ridge, Tennessee 37831; prices available from (423) 576-8401, FTS 626-8401.

Available to the public from the National Technical Information Service, U. S. Department of Commerce, 5285 Port Royal Rd., Springfield, Virginia 22161, (703) 487-4650.

Copyright ( 1999 by AlliedSignal Inc. The Government is granted for itself and others acting on its behalf a paid-up, nonexclusive, irrevocable worldwide license in this data to reproduce, prepare derivative works, and perform publicly and display publicly.

A prime contractor with the United States Department of Energy under Contract Number DE-ACO4-76-DP00613.
AlliedSignal Inc.

Federal Manufacturing \& Technologies P. O. Box 419159 Kansas City, Missouri 64141-6159 
KCP-613-6212

Distribution Category UC-706

Approved for public release; distribution is unlimited.

\title{
HIGH BREAKDOWN STRENGTH, MULTILAYER CERAMICS FOR COMPACT PULSED POWER APPLICATIONS
}

\author{
M. L. Krogh and \\ B. C. Schultz, FM\&T; \\ W. Huebner, \\ S. C. Zhang, and \\ B. Gilmore, University of Missouri-Rolla; \\ R. C. Pate, \\ L. F. Rinehart, and \\ J. M. Lundstrom, Sandia National Laboratory/New Mexico \\ Published July 1999 \\ Paper submitted to $12^{\text {th }}$ International Pulsed Power Conference 1999 \\ June 27-30, 1999 \\ Monterey, CA
}




\title{
HIGH BREAKDOWN STRENGTH, MULTILAYER CERAMICS FOR COMPACT PULSED POWER APPLICATIONS
}

\author{
W. Huebner, S.C. Zhang, B. Gilmore \\ University of Missouri-Rolla, Rolla, Missouri, USA \\ M.L. Krogh, B.C. Schultz \\ AlliedSignal FM\&T, Kansas City, Missouri, USA \\ R. C. Pate, L. F. Rinehart, J. M. Lundstrom \\ Sandia National Laboratory, New Mexico, USA
}

\begin{abstract}
Advanced ceramics are being developed for use in large area, high voltage devices in order to achieve high specific energy densities $\left(>10^{6} \mathrm{~J} / \mathrm{m}^{3}\right)$ and physical size reduction. Initial materials based on slip cast $\mathrm{TiO}_{2}$ exhibited a high bulk breakdown strength (BDS >300 $\mathrm{kV} / \mathrm{cm})$ and high permittivity with low dispersion $\left(\varepsilon^{\sim} 100\right)$. However, strong area and thickness dependencies were noted. To increase the BDS, multilayer dielectric compositions are being developed based on glass $/ \mathrm{TiO}_{2}$ composites. The addition of glass increases the density ( $\sim 99.8 \%$ theoretical), forms a continuous grain boundary phase, and also allows the use of high temperature processes to change the physical shape of the dielectric. The permittivity can also be manipulated since the volume fraction and connectivity of the glassy phase can be readily shifted. Results from this study on bulk breakdown of $\mathrm{TiO}_{2}$ multilayer structures with an area of $2 \mathrm{~cm}^{2}$ and $0.1 \mathrm{~cm}$ thickness have measured $650 \mathrm{kV} / \mathrm{cm}$. Furthermore, a strong dependence of breakdown strength and permittivity has been observed and correlated with microstructure and the glass composition. This paper presents the interactive effects of manipulation of these variables.
\end{abstract}

\section{INTRODUCTION}

Dielectrics for pulsed power applications need to satisfy several key material and processing parameters [1], including a high voltage hold off $(=300 \mathrm{kV})$, a high, nondispersive permittivity $(\varepsilon \sim 100$ to 400$)$, surface flashover inhibition at the edge, the ability to be triggered by surface flashover switching, and the ability to be fabricated into various shapes and sizes.

Higher voltages and permittivities result in greater stored energy density and hence smaller systems. Current systems based on water dielectrics can hold off 150 $\mathrm{kV} / \mathrm{cm}$, have a $\varepsilon^{\sim} 80$, and are self-healing [1]. Their replacement by a solid system such as a polymer or ceramic is highly desirable, but currently available systems based on polymers [2] or ceramics [3] are insufficient due to fundamental shortcomings.

This work focused on improving the microstructure and composition of ceramic-based systems, with particular emphasis on increasing the BDS and $\varepsilon$. The primary source of voltage failure for a ceramic is related

* Operated for the United States Department of Energy under contract \#DE-AC04-76-DP00613 to the presence of porosity [4,5], and the associated field/stress amplification. By adding a high BDS, low $\varepsilon$ glass to a higher $\varepsilon$ dielectric, the porosity can be virtually eliminated, and the BDS is increased. Here we report on studies on glass-loaded $\mathrm{TiO}_{2}$ dielectrics, with additional improvements in processing methodology.

\section{EXPERIMENTAL PROCEDURE}

In this work $\mathrm{TiO}_{2}$ (HG TICON, TAM Ceramics, NY) was used as the base dielectric. $\mathrm{TiO}_{2}$ has a nondispersive $\varepsilon^{\sim} 110$, and hence is similar to water. The $\mathrm{TiO}_{2}$ was prepared by both slip and tape casting. Compositional modifications included additions of a glassy phase.

\section{A. Slip Cast Dielectrics}

The fabrication of dielectrics with dimensions on the order of a meter rules out many processing techniques, hence slip casting was initially pursued. Through a series of rheological studies, an optimized slurry suitable for slip casting was developed: 50 vol\% $\mathrm{TiO}_{2}, 0.25 \mathrm{wt} \%$ PVA based on solids (binder for green strength), $0.8 \mathrm{mg} / \mathrm{m}^{2}$ Darvan C (dispersant) and a $\mathrm{pH}^{\sim} 10$ (electrostatic dispersion). This slurry was cast into large disks (up to 10 " diameter) using plaster-of-paris molds, sintered to $\sim 97 \%$ density at $1400^{\circ} \mathrm{C}-6 \mathrm{~h}$, and then planar-lapped to a $12 \mu$ inch finish.

\section{B. Tape Cast Dielectrics}

Tape cast dielectrics were fabricated by doctor blading a slurry of $50 \quad$ vol\% $\quad \mathrm{TiO}_{2}$ dispersed in a nonaqueous binder system (MSI Ferro, CA.) Individual tape layers were $0.20 \mathrm{~mm}$ thick. Multilayer structures were fabricated by screen printing tapes with a Pt thick film ink, followed by lamination up to the desired thickness. Structures were dried for 5 days at $140^{\circ} \mathrm{C}$, and calcined at $450^{\circ} \mathrm{C}$ for 5 days $\left(1^{\circ} \mathrm{C} / \mathrm{min}\right.$ heating rate). Sintering was performed at varying temperatures to vary the grain size and density.

\section{Glass Composites}

The target microstructure has a 0-3 connectivity; i.e. a continuous, glassy grain boundary surrounding $\mathrm{TiO}_{2}$ grains. A useful glassy phase needs to exhibit several key properties, including: a) the glass must "wet" the dielectric, but not react with it in a fashion detrimental to the electrical properties, b) the glass must result in higher densities, and c) the glass must exhibit a high electrical 
resistivity, as well as a high electrical breakdown strength. Borosilicate glasses were chosen for these reasons [1]. Table I summarizes the composition and properties of glasses made by melt fining and quenching. Volume fractions of these glasses ranging from $5-20 \%$ were added to the $\mathrm{TiO}_{2}$ by ball milling, and then microstructural evolution studies were performed to optimize the density and minimize the grain size. Test specimens were tape cast as described above.

Table I. Properties of the Candidate Glasses

\begin{tabular}{|cccccccc|}
\hline Glass & Comp. & $\begin{array}{c}\mathrm{T}_{\mathrm{m}} \\
\left({ }^{\circ} \mathrm{C}\right)\end{array}$ & $\begin{array}{c}\text { Density } \\
(\mathrm{g} / \mathrm{cc})\end{array}$ & $\begin{array}{c}\rho \\
(? \cdot \mathrm{cm})\end{array}$ & $\mathrm{K}$ & $\begin{array}{c}\mathrm{BDS} \\
(\mathrm{V} / \mathrm{mil})\end{array}$ & $\phi$ \\
\hline $\mathrm{B}$ & $\mathrm{SiO}_{2}-\mathrm{B}_{2} \mathrm{O}_{3}$ & 1200 & 2.06 & $=10^{16}$ & 4 & 1900 & $58^{\circ}$ \\
\hline $\mathrm{C}$ & $\begin{array}{c}\mathrm{SiO}_{2}-\mathrm{B}_{2} \mathrm{O}_{3} \\
\mathrm{CaO}\end{array}$ & 1000 & 2.72 & $\sim 10^{15}$ & 8.5 & 2060 & $8^{\circ}$ \\
\hline $\mathrm{D}$ & $\begin{array}{c}\mathrm{SiO}-\mathrm{B}_{2} \mathrm{O}_{3} \\
\mathrm{CaO}, \mathrm{Al}_{2} \mathrm{O}_{3}\end{array}$ & 1100 & 2.18 & $\sim 10^{14}$ & 4 & $>1900$ & $28^{\circ}$ \\
& & & & & & \\
\hline
\end{tabular}

\section{RESULTS AND DISCUSSION}

\section{A. Slip Cast Titania}

Initial studies focused on the influence of dielectric thickness and area on the breakdown strength of slip cast $\mathrm{TiO}_{2}$. This approach was pursued in the interest of ultimately producing $1 \mathrm{~m}$ diameter components. For example, Figure 1 shows an 8 " diameter test specimen with sputtered-Au electrodes. To explore thickness effects on the D.C. breakdown strength, $1.25 \mathrm{~cm}$ diameter test specimens with a $0.25 \mathrm{~cm}$ hemispherical cathode and a planar anode were used. All measurements were performed in silicon oil. Figure 2 exhibits the results. Clearly the intrinsic breakdown strength of the dielectric is on the order of $750 \mathrm{kV} / \mathrm{cm}$, but as a larger volume is stressed the breakdown strength decreased. A series of studies on the relationship between the microstructure and BDS led to the conclusion that the critical flaw size leading to this thickness dependency was on the order of $25-50 \mu \mathrm{m}$. These samples were all $\sim 96 \%$ dense, hence the presence of even 4 vol\% porosity did not seriously impact the BDS. Using results from Gerson [5] we might expect that the intrinsic BDS would be $\sim 25 \%$ higher for $100 \%$ dense samples. The high grain boundary mobility

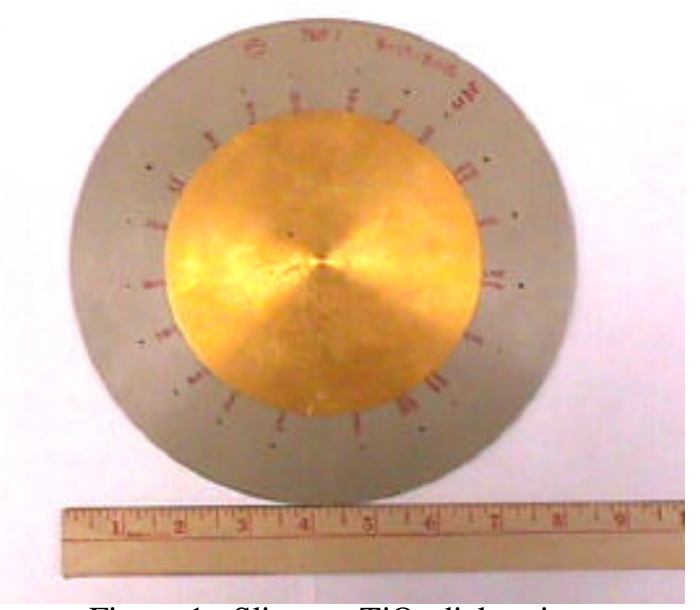

Figure 1. Slip cast $\mathrm{TiO}_{2}$ dielectric.

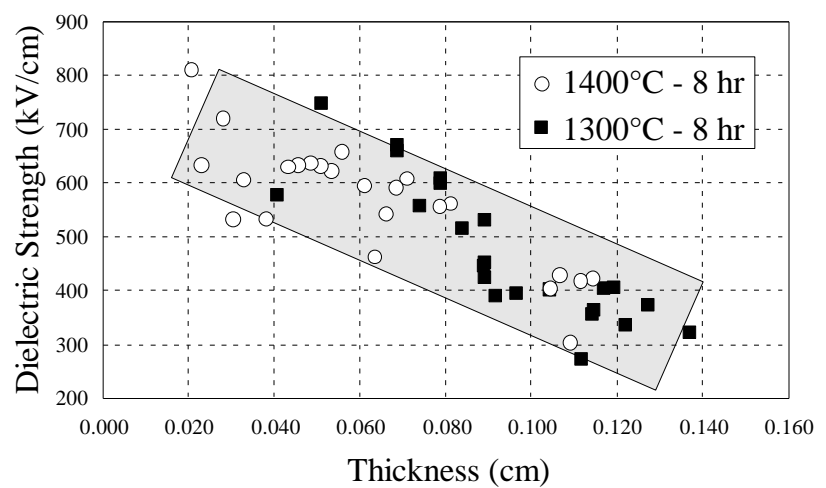

Figure 2. BDS as a function of dielectric thickness for slip cast $\mathrm{TiO}_{2}$.

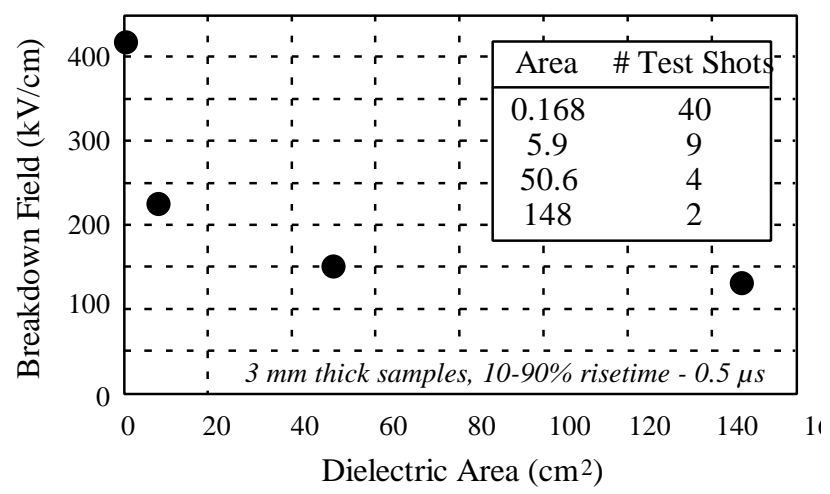

Figure 3. BDS as a function of electrode area for slip cast $\mathrm{TiO}_{2}$ dielectrics.

of $\mathrm{TiO}_{2}$ at these temperatures leads to mostly intragranular, spherical porosity. Spherical, $3 \mu \mathrm{m}$ pores obviously do not strongly degrade the BDS.

Figure 3 shows the effect of stressed area on the BDS, using $0.3 \mathrm{~cm}$ thick planar samples as shown in Figure 1. Similar to the thickness dependency, larger area samples had significantly lower BDSs. Ultimately, the BDS appeared to be $\sim 100 \mathrm{kV} / \mathrm{cm}$ for larger area, thick parts. This was deemed unsuitable for the purposes of the desired pulsed power components.

\section{B. Tape Cast Titania with Glass Phase Additions}

\section{1) Microstructural Evolution}

The ability to fabricate a dense, composite dielectric with a glassy grain boundary is predicated on the ability of the glass to wet the dielectric. Table I contains the contact angle of the various glasses on $\mathrm{TiO}_{2}$ taken from the SEM micrographs shown in Figure 4. Glass C wets the best, followed by the $\mathrm{D}$ and $\mathrm{C}$ glasses. All three can be used to create a continuous grain boundary phase, depending upon the volume fraction $\left(\mathrm{V}_{\mathrm{f}}\right)$ of glass which is added. For instance, Figures 5 and 6 show SEM micrographs of 5 and $10 \mathrm{vol} \%$ additions of B glass. The 5 vol\% addition resulted in a high density, but a discontinuous glass phase. Comparatively, the 10 vol\% addition resulted in a nearly model microstructure, with virtually no porosity, and a continuous glassy grain boundary with a uniform thickness. The grain size is substantially larger, which is not as desirable in terms of ultimate BDS. 


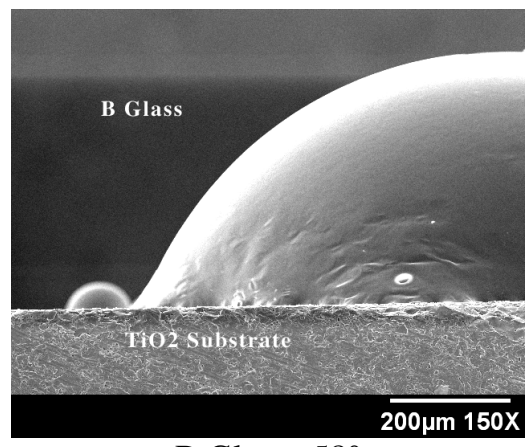

B Glass: $58^{\circ}$

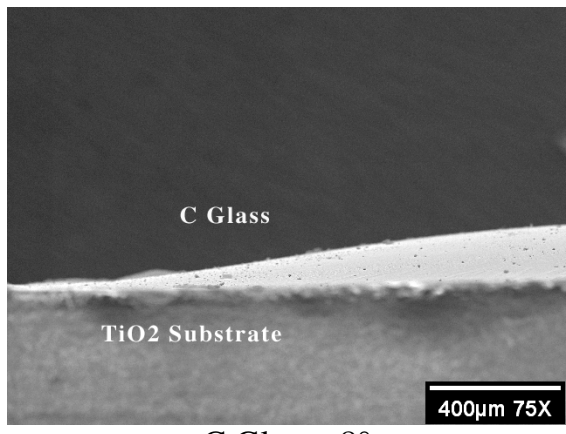

C Glass: $8^{\circ}$

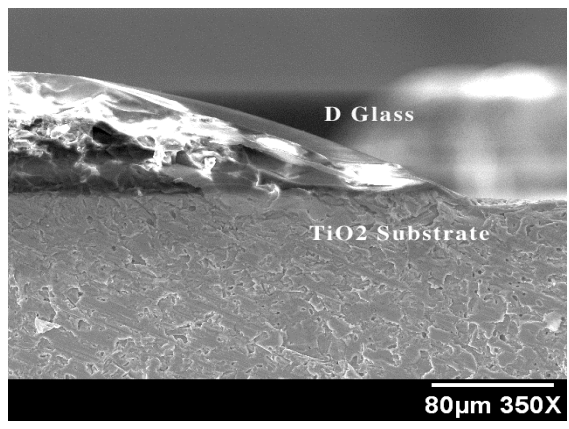

D Glass: $28^{\circ}$

Figure 4. SEM micrographs of the wetting angle of glass droplets fired onto the $\mathrm{TiO}_{2}$ dielectric.

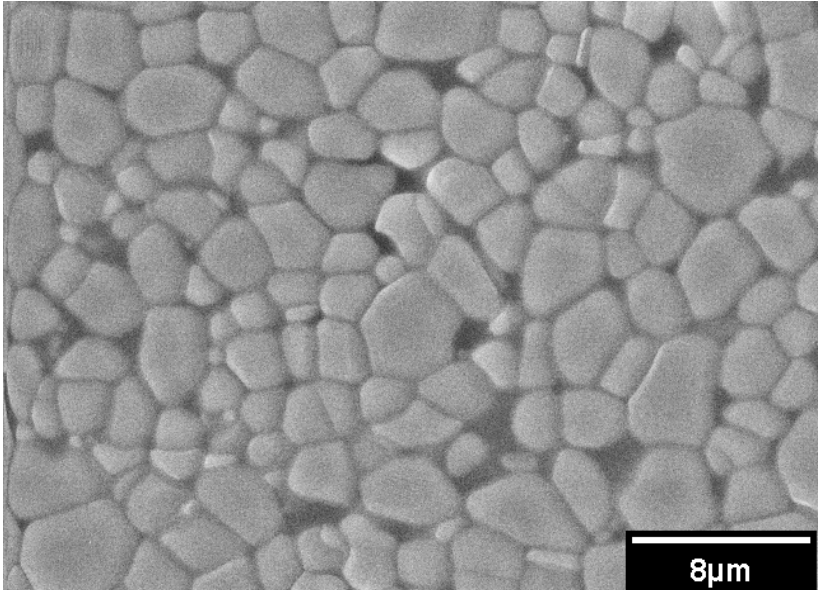

Figure 5. SEM micrograph of a $\mathrm{TiO}_{2}$ dielectric with 5 vol\% $\mathrm{B}$ glass additions.

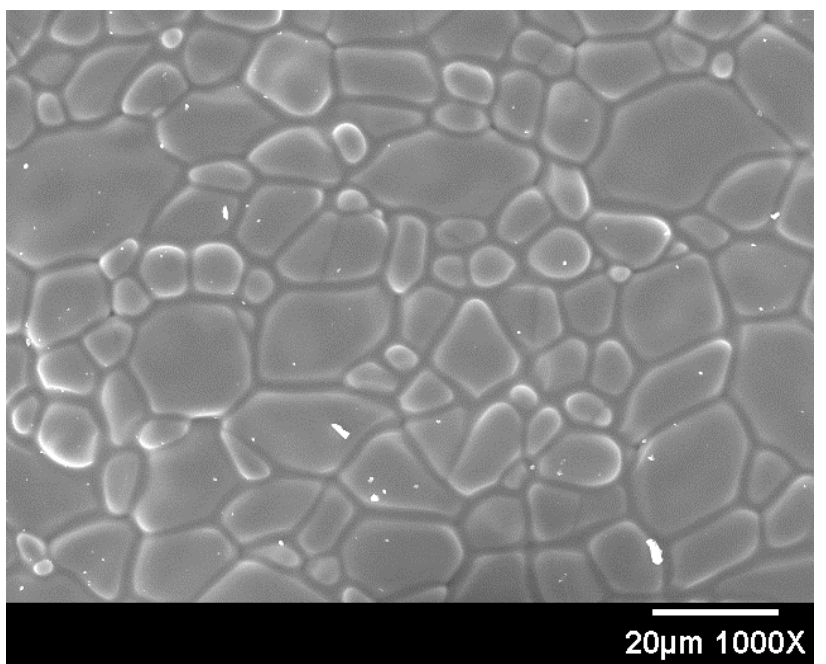

Figure 6. $\mathrm{TiO}_{2}$ dielectric with 10 vol\% $\mathrm{B}$ glass additions.

\section{2) Electrical Properties}

Certainly the presence of a low $\mathrm{K}$ glass in the grain boundary will decrease the overall $\mathrm{K}$, the extent of which will depend on the $\mathrm{V}_{\mathrm{f}}$ and thickness of the glassy grain boundary. Figure 7 exhibits the variation in $\mathrm{K}_{\text {with }} \mathrm{V}_{\mathrm{f}}$ of the $\mathrm{B}$ glass. Pure $\mathrm{TiO}_{2}$ has a $\mathrm{K}^{\sim} 110$. Additions of up to 20 vol\% decreased the $\mathrm{K}$ to $\sim 70-85$, depending upon the soak time. Longer sintering times increases the grain size

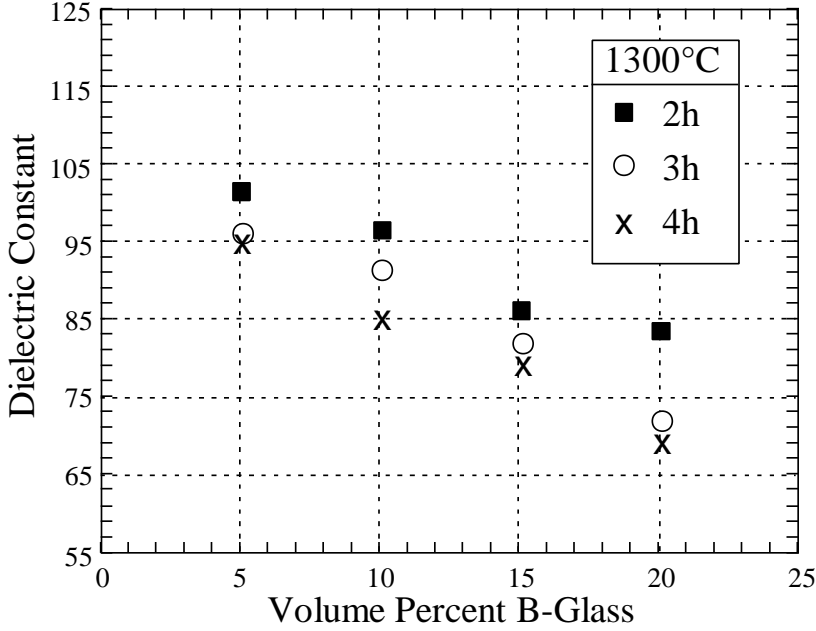

Figure 7. Effect of volume percent B-glass on the K.

and the thickness of the glassy grain boundary, resulting in an overall lower $\mathrm{K}$.

The ultimate purpose of this investigation was to study the influence of a glassy grain boundary on the BDS. Table II summarizes the BDS results for all three glasses as a function of volume fraction and soak time at $1300^{\circ} \mathrm{C}$, along with pure $\mathrm{TiO}_{2}$ for comparison. These results can be summarized as follows:

- Compared to pure $\mathrm{TiO}_{2}$, all three glasses yielded higher BDSs. This is attributable to the higher densities which were achieved and the uniform microstructures.

- The BDS tracked closely with the density $\rightarrow$ higher densities yielded higher BDSs, although exceptions exist due to changes in the grain size. For the most part, the 10 vol\% samples exhibited the highest BDS.

- In this study the $\mathrm{D}$ glass yielded the best properties, with a BDS $1650 \mathrm{~V} / \mathrm{mil}(650 \mathrm{kV} / \mathrm{cm})$. This is very encouraging, and ongoing studies are focused on understanding why this composition yielded the highest BDS. This result cannot be explained on the basis of any fundamental glass properties or the resultant microstructures (which were similar between specimens).

Figure 8 graphically depicts the variation in BDS with soak time for the B glass. The maximum exhibited by the glasses occurs at the point where the density is a maximum, and the grain size is a minimum. Longer soak 
Table II. Influence of Processing Conditions on the Breakdown Strength and Density of the Tape $\mathrm{Cast}^{\mathrm{TiO}_{2}}$ Dielectrics

\begin{tabular}{|c|c|c|c|c|c|c|c|c|c|c|c|}
\hline & \multicolumn{2}{|c|}{1 hour } & \multicolumn{2}{|c|}{2 hour } & \multicolumn{2}{|c|}{3 hour } & \multirow{2}{*}{\multicolumn{2}{|c|}{$\begin{array}{l}4 \text { hour } \\
\rho \text { BDS }\end{array}$}} & \multicolumn{2}{|c|}{6 hour } \\
\hline & & $\rho$ & BDS & & BDS & $\rho$ & BDS & & & $\rho$ & BDS \\
\hline & & $(\%)$ & $\mathrm{V} / \mathrm{mil}$ & $(\%)$ & $\mathrm{V} / \mathrm{mil}$ & $(\%)$ & $\mathrm{V} / \mathrm{mil}$ & $(\%)$ & V/mil & $(\%)$ & $\mathrm{V} / \mathrm{mil}$ \\
\hline 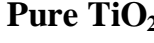 & & 89.1 & 590 & 92.5 & 895 & & & 94.0 & 770 & & \\
\hline $1 \% \mathrm{ZrO}_{2}$ & & 89.2 & 810 & 91.6 & 1060 & & & 95.4 & 950 & & \\
\hline B Glass & $5 \%$ & 92 & 994 & 94.7 & 1041 & 95.7 & 1114 & 96.5 & 1184 & 97.6 & 983 \\
\hline & $10 \%$ & 94 & 1006 & 97 & 994 & 97.7 & 1039 & 98.4 & 965 & 98.7 & 959 \\
\hline & $15 \%$ & 95.8 & 1285 & 98.8 & 1107 & 98.5 & 1054 & 99.4 & 1317 & 99.8 & 919 \\
\hline & $20 \%$ & 93.3 & 779 & 97.6 & 1072 & 99 & 1273 & 99.4 & 904 & 99.8 & 1033 \\
\hline C Glass & $5 \%$ & 95.5 & & 96.5 & 976 & & & 97.1 & 874 & & \\
\hline & $10 \%$ & 98.6 & 1128 & 97.7 & 1192 & & & 98.3 & 628 & 98.7 & 215 \\
\hline & $15 \%$ & 97.9 & & 99.6 & 1113 & & & 99.8 & & & \\
\hline & $20 \%$ & 97.4 & & 99.1 & 1016 & & & 99.8 & & & \\
\hline D Glass & $5 \%$ & 94.6 & & 96.8 & 1140 & & & 98.3 & & & \\
\hline & $10 \%$ & 97.1 & 1006 & 98.7 & 1650 & & & 97.7 & 1290 & 98.8 & 1342 \\
\hline & $15 \%$ & 99.8 & & 99.0 & 1162 & & & 99.3 & 1256 & & \\
\hline & $20 \%$ & 99.8 & 1068 & 99.8 & 1167 & & & 99.8 & 1246 & & \\
\hline
\end{tabular}

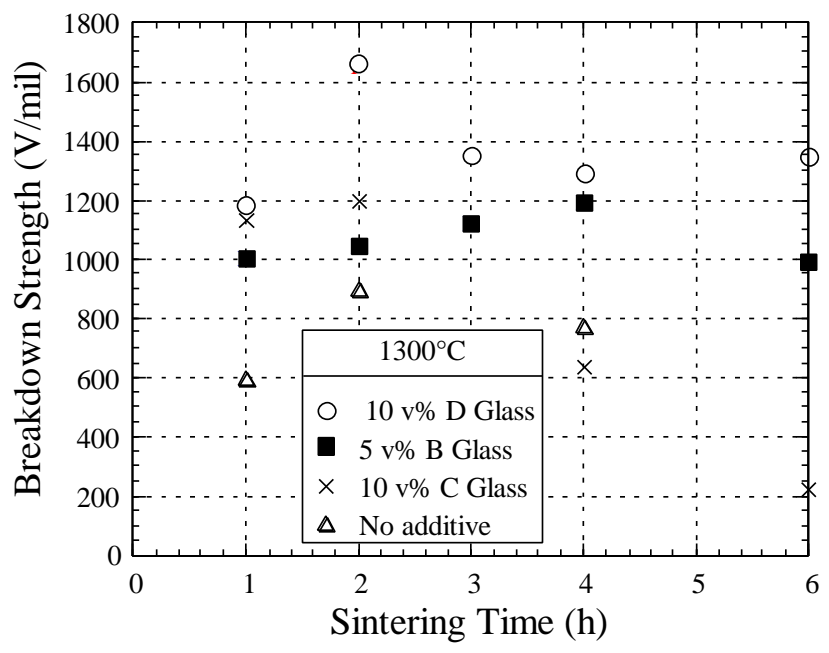

Figure 8. Effect of sintering soak time on the BDS.

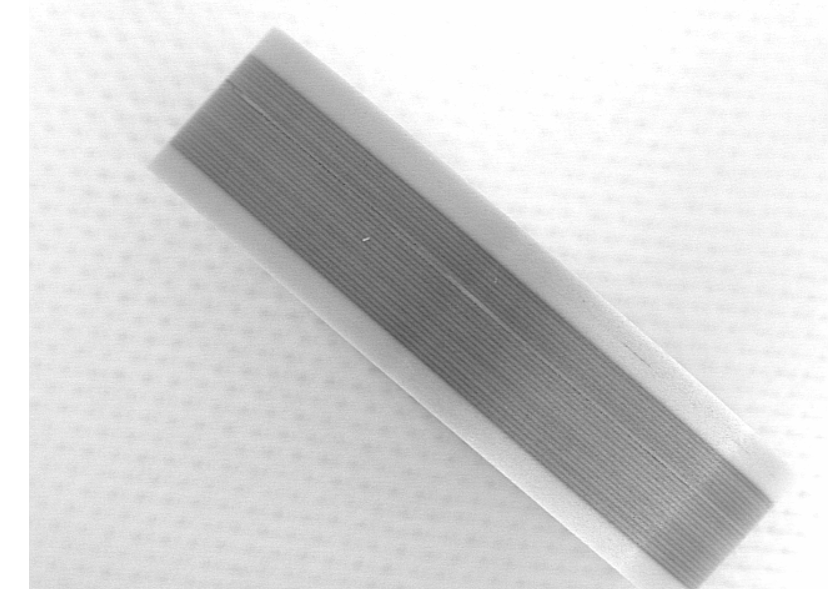

Figure 9. 1.1" diameter, multilayer $\mathrm{TiO}_{2}$ with 25 layers of Pt internal electrodes.

permittivity. The energy density of these dielectrics is on the order of $1 \mathrm{MJ} / \mathrm{m}^{3}$, and as such show great promise for compact pulsed power applications.

\section{REFERENCES} metallic film within a dielectric increases not only its bulk breakdown strength, but also the surface flashover voltage. This structure is called the "Ultrahigh Gradient Insulator." Tape casting can readily be used to produce 22 structures, hence work is underway to incorporate the glass-loaded systems into this configuration. Figure 9 shows the first insulator produced in this manner; this insulator has 25 layers of $\mathrm{TiO}_{2}$ with internal Pt electrodes. No electrical tests have been performed as of this writing.

\section{SUMMARY}

Through modification of the microstructure with glass phase additions the bulk BDS of titania dielectrics has been substantially increased. The addition of glass increases the density, forms a continuous grain boundary phase, and allows for systematic control of the
[1] S.T. Pai and Q. Zhang, Introduction to High Power Pulse Technology, World Scientific Publishing Co., Singapore.

[2] Z. Deheng and Y. Zhang, High Voltage Electrical Insulation, Tsinghua University Press, Beijing (1992).

[3] I.O. Owate and R. Freer, "Dielectric breakdown of ceramics and glass ceramics," in Proc. $6^{\text {th }}$ Intl Conf. on Dielectric Materials, Measurements and Applications, 1992, p. 443.

[4] R. Gerson and T.C. Marshall, "Dielectric Breakdown of Porous Ceramics," J. Appl. Phys., vol. 30, pp. 1650-1653, Nov. 59.

[5] G. Economos, "The Effect of Microstructure on the Electrical and Magnetic Properties of Ceramics," Ceramic Fabrication Processes, W.D. Kingery, Ed., New York, John Wiley \& Sons, 1950, pp. 201-213. 
